Review

\title{
What Is the Appropriate Clinical Target Volume for Esophageal Squamous Cell Carcinoma? Debate and Consensus Based on Pathological and Clinical Outcomes
}

\author{
Dali Han ${ }^{1,3}$, Yinping Yuan ${ }^{2,3}$, Xuqing Song4, Yonghua Y $\mathbf{u}^{1,3}$, Jinming $Y \mathbf{u}^{1,3,}$, \\ 1. Department of Radiation Oncology, Shandong University Affiliated Shandong Cancer Hospital and Institute, Jinan, Shandong Province, China. \\ 2. Department of Pathology, Shandong University Affiliated Shandong Cancer Hospital and Institute, Jinan, Shandong Province, China. \\ 3. Shandong Province Key Laboratory of Radiation Oncology, Jinan, Shandong Province, China. \\ 4. Department of Radiation Oncology, Jining Cancer Hospital, Jining, Shandong Province, China \\ $\square$ Corresponding author: Jinming Yu, Jiyan Road 440, Jinan City, China. Phone Number: 86531 67626971, Email: 201220538@Mail.Sdu.Edu
}

(0) Ivyspring International Publisher. Reproduction is permitted for personal, noncommercial use, provided that the article is in whole, unmodified, and properly cited. See http://ivyspring.com/terms for terms and conditions.

Received: 2015.09.16; Accepted: 2015.10.18; Published: 2016.01.01

\begin{abstract}
Accurate delineation of clinical target volume (CTV) is critical in the effective management of squamous cell carcinoma (SCC) of esophagus using radiation therapy. Accurate delineation may improve the probability of local control and reduce the risk of complications. However, there are no consistent standards on the proper size of the margins added to the gross tumor volume (GTV). Different institutions and radiation oncologists have discordant opinions. In this paper, we review pathological and clinical outcomes to determine the most appropriate CTV for squamous cell carcinomas (SCC) of esophagus. The CTV for esophageal carcinoma should ensure that all subclinical lesions are encompassed regardless of the physical distance. The most precise method for delineating a reasonable CTV is to combine advanced imaging techniques, such as PET/CT and EUS, which allows the detection and prediction of subclinical lesions based on tumor characteristics such as the pathological type, differentiation, T disease, length and lymph node status.
\end{abstract}

Key words: esophageal squamous cell carcinoma, radiation therapy, clinical target volume

\section{Introduction}

Radiation therapy is one of the most important therapeutic methods in the treatment of esophageal squamous cell carcinoma (ESCC); however, the overall survival and local control rates for this disease remain unsatisfactory. The two-year survival rate is only $30-40 \%$, and the local recurrence rate is over $50 \%$ after radiation with or without chemotherapy $[1,2]$. The accurate delineation of the clinical target volume (CTV) in ESCC plays a very important role in disease control. However, there are no consistent standards for constructing the proper CTV based on the gross tumor volume (GTV). Different methods opinions have been reported.

In this paper, we review pathological and clinical outcomes reported in the literature to determine the most appropriate CTV margin in patients with ESCC treated with radiation therapy. As the biological behavior of adenocarcinoma of esophagus differs substantially from that of SCC, the scope this review does not address the CTV of adenocarcinoma.

\section{Design of the CTV in esophageal SCC in conventional radiation therapy}

The CTV for esophageal squamous cell carcinoma should include the primary tumor and its corresponding subclinical lesions (described below), which typically arise within the esophagus itself and its regional lymphatics. Different selections of margin 
size for creating CTV based on the GTV have been reported. However, in conventional radiation therapy, areas at risk for subclinical esophageal carcinoma were commonly included using 3-4-cm margins in the craniocaudal direction from the GTV (following the course of the esophagus) and a $1-\mathrm{cm}$ margin in the lateral and anteroposterior directions from the GTV. Whether such practice remains appropriate in the precision radiation therapy era needs to be reviewed.

\section{(1) Consideration of pathologic outcomes}

CTVs of radiation therapy of esophageal SCC should cover the primary tumor and its secondary lesions, which may or may not be apparent on imaging studied. The secondary lesions frequently include direct invasion (DI), intra-mural metastasis (IMM), multicentric occurrent lesions (MOL), vascular invasion (VI), microscopic lymph node metastasis (LNMM) and isolated tumor cells (ITC). Recently, perineural invasion (PNI) has been included as a secondary lesion. Kuwano et al. [3] performed serial histologic investigations by measuring the length of the subepithelial extension of the lesion beneath the noncancerous epithelium and reported that coexisting secondary lesions predicted a poor prognosis. Based on this information, we believe that the presence of secondary lesions is closely related to the prognosis of patients with esophageal carcinoma; patients with a larger number of secondary lesions have a poorer prognosis.

a) DI: involves the intramucosal, submucosal and muscular layers. These secondary lesions may infiltrate in all directions from the main tumor. $\mathrm{Ku}-$ wano et al. [3] through the research of 17 patients with positive subepithelial extension of esophageal carcinoma, and reported that the mean depth of invasion is $4.11 \mathrm{~mm}$ (range: $1.2 \mathrm{~mm}-9.5 \mathrm{~mm}$ ), and Tsutsui et al. [4] in similarly research reported that DI is generally less than $30 \mathrm{~mm}$ in early-stage esophageal SCC.

b) IMM: is also known as salutatory metastasis. IMM is defined using the following standard macroscopic and histologic criteria: (1) clearly separated from the primary tumor; (2) located in the esophageal wall; (3) has the gross appearance of a submucosal tumor without intra-epithelial extension of the tumor; (4) has the same histologic type as the primary tumor; and (5) lacks any evidence of intravascular growth. Different papers have reported the incidence of IMM as ranging from $4.19 \%$ to $26 \%$ in ESCC, and the distance of IMM spread from the primary tumor is $0.1 \mathrm{~cm}$ to $13 \mathrm{~cm}$, with a maximum cranial distance of $13 \mathrm{~cm}$ and a maximum caudal distance of $9.5 \mathrm{~cm}$ (as shown in Table 1). Kato et al. [7] reported that IMM is strongly correlated with lymph node metastasis. Although most research has shown that IMM is strongly correlated with overall prognosis [5-9], the incidence and distance of IMM remains controversial.

Table 1. IMM in esophageal carcinoma: incidence, distance from the primary tumor and survival

\begin{tabular}{|c|c|c|c|c|c|c|}
\hline Authors & $\begin{array}{l}\text { Num- } \\
\text { ber of } \\
\text { patients }\end{array}$ & Pathological type & Technique & $\begin{array}{l}\text { IMM } \\
\text { incidence } \\
(\%)\end{array}$ & IMM distance $(\mathrm{cm})$ & Survival analysis \\
\hline $\begin{array}{l}\text { Nishimaki et } \\
\text { al. [5] }\end{array}$ & 324 & $\begin{array}{l}\text { Squamous carcinoma } 300 \\
\text { cases, Undifferentiated } \\
\text { carcinoma } 15 \text { cases, Ade- } \\
\text { nocarcinoma } 8 \text { cases, } \\
\text { Carcinosarcoma } 1 \text { case }\end{array}$ & Macropathology & 16.7 & $\begin{array}{l}0.1-13.0 \mathrm{~cm} \text {; median } 1.5 \mathrm{~cm} \text { (un- } \\
\text { specified cranial or caudal direc- } \\
\text { tion) }\end{array}$ & $\begin{array}{l}\text { IMM group 5-year survival rate } 0 ; \\
\text { Non-IMM group } 5 \text {-year survival rate } \\
40.6-45.5 \% ; P<0.001\end{array}$ \\
\hline $\begin{array}{l}\text { Takubo et al. } \\
\text { [6] }\end{array}$ & 201 & Squamous carcinoma & Serial section & 11.9 & $\begin{array}{l}\text { Cranial maximum } 13.0 \mathrm{~cm} \\
\text { Caudal maximum } 7.0 \mathrm{~cm}\end{array}$ & $\begin{array}{l}\text { IMM group 5-year survival rate } 9 \% \\
\text { Non-IMM group 5-year survival rate } 25 \% \\
P<0.001\end{array}$ \\
\hline Kato et al. [7] & 393 & Squamous carcinoma & Macropathology & 15.3 & - & $\begin{array}{l}\text { IMM group 5-year survival rate } 11.9 \% \text {; } \\
\text { Non-IMM group 5-year survival rate } \\
42.6 \% ; P<0.001\end{array}$ \\
\hline $\begin{array}{l}\text { Maeta et al. } \\
{[29]}\end{array}$ & 111 & Squamous carcinoma & Serial section & 9.0 & $\begin{array}{l}\text { Cranial range: } 0.6-8.1 \mathrm{~cm} \text {, mean } \\
3.4 \mathrm{~cm} \\
\text { Caudal range: } 2.2-8.6 \mathrm{~cm} \text {, mean } \\
4.6 \mathrm{~cm}\end{array}$ & $\begin{array}{l}\text { IMM group 5-year survival rate } 20 \% \text {; } \\
\text { Non-IMM group 5-year survival rate } \\
24.9 \% ; P>0.05\end{array}$ \\
\hline $\begin{array}{l}\text { Kuwano et al. } \\
{[8]}\end{array}$ & 167 & Squamous carcinoma & Serial section & 14.4 & - & $\begin{array}{l}\text { IMM group survival time } 1469 \pm 580 \mathrm{~d} ; \\
\text { Non-IMM group survival time } 2589 \pm 349 \\
\mathrm{~d} ; P<0.001\end{array}$ \\
\hline Lam et al. [13] & 96 & Squamous carcinoma & Serial section & 26.0 & $\begin{array}{l}\text { Cranial: } 0.5-7.7 \mathrm{~cm} \text {, mean } 3.4 \mathrm{~cm} \\
\text { Caudal: } 0.5-9.5 \mathrm{~cm} \text {, mean } 4.0 \mathrm{~cm}\end{array}$ & - \\
\hline $\begin{array}{l}\text { Szántó et al. } \\
\text { [30] }\end{array}$ & 143 & Adenocarcinoma & Macropathology & 4.2 & $\begin{array}{l}2.0-5.0 \mathrm{~cm} \text {, mean } 3.8 \mathrm{~cm}(\mathrm{Un}- \\
\text { specified cranial or caudal direc- } \\
\text { tion) }\end{array}$ & Median survival time $141 \mathrm{~d}$ \\
\hline Yuasa et al. [9] & 212 & Squamous carcinoma & Serial section & 10.9 & $\begin{array}{l}0.5-7.0 \mathrm{~cm} \text {, mean } 2.7 \mathrm{~cm}(\mathrm{Un}- \\
\text { specified cranial or caudal direc- } \\
\text { tion) }\end{array}$ & $\begin{array}{l}\text { IMM group } 5 \text {-year survival rate } 9.0 \% \text {, } \\
\text { mean survival time } 0.7 \text { years; Non-IMM } \\
\text { group } 5 \text {-year survival rate } 42 \% \text {, mean } \\
\text { survival time } 2 \text { years, } P<0.001\end{array}$ \\
\hline
\end{tabular}

Note: - , Not assessed; IMM, intra-mural metastasis; d, day. 
c) MOL: must be distinguished from a second carcinoma of non-esophagus origin and other lesions, such as IMM, and should be defined by the following strict diagnostic criteria [10,11]: (1) each lesion has definite malignant features by pathological analysis; (2) the individual lesions are discontinuous; (3) the main tumor and secondary tumor coexist simultaneously; (4) the main tumor is comparatively larger and more deeply invasive; (5) secondary tumor lesions usually include intraepithelial carcinomas, such as atypical hyperplasia and carcinoma in situ, and a metastatic lesion should be excluded; and (6) the tumor is located in the esophagus or the gastroesophageal junction. Secondary tumors that occur after a primary esophageal carcinoma (approximately 1 year later) are usually known as heterochronic multi-esophageal carcinoma and should not be included in the MOL category.

Each institution has reported different results. The incidence of MOL is $20.2-31 \%$ in esophageal SCC patients who did not receive preoperative irradiation.
The cranial distance from the primary tumor was $0.88-7.14 \mathrm{~cm}$, and the caudal distance was $0.57-6.26 \mathrm{~cm}$ (Table 2). The incidence of MOL in patients administered preoperative irradiation was lower than patients who did not receive preoperative radiation. Kuwano et al. reported that the MOL rate was $11.7 \%(19 / 162)$ in patients who received preoperative irradiation and $25.6 \%(11 / 143)$ in patients who did not receive preoperative irradiation [10]. Tsutsui et al. reported that the MOL rate among 303 patients, most of whom were administered preoperative irradiation, was only $5.61 \%(17 / 303)$ [11]. These data show that irradiation can kill some MOLs. MOLs appear to have an adverse prognostic effect in patients with ESCC, although currently there are no independent reports of this effect. MOLs are more likely in patients with certain risk factors, including male sex, heavy drinking or smoking, and a family history of upper digestive tract carcinoma [12]. The CTV margin should be enlarged appropriately if these risk factors are noted.

Table 2. MOL in esophageal carcinoma: incidence, distance from the primary tumor and survival

\begin{tabular}{|c|c|c|c|c|c|c|}
\hline Authors & $\begin{array}{l}\text { Number of } \\
\text { patients }\end{array}$ & Pathological type & Technique & MOL incidence (\%) & MOL distance (mm) & Survival analysis \\
\hline Tsutsui et al. [4] & 303 & Squamous carcinoma & Serial section & 5.6 & - & - \\
\hline Maeta et al. [29] & 111 & Squamous carcinoma & Serial section & 20.7 & $\begin{array}{l}\text { Cranial: } 0.88-7.14 \mathrm{~cm} \text {, mean } 2.6 \mathrm{~cm} \\
\text { Caudal: } 0.57-6.26 \mathrm{~cm} \text {, mean } 2.6 \mathrm{~cm}\end{array}$ & $\begin{array}{l}\text { MOL group 5-year sur- } \\
\text { vival rate } 33.4 \% \text {; } \\
\text { Non-MOL group 5-year } \\
\text { survival rate } 24.9 \% ; P>0.05\end{array}$ \\
\hline Kuwano et al. [10] & 205 & Squamous carcinoma & - & $\begin{array}{l}14.6 \text { (with preopera- } \\
\text { tive irradiation } \\
11.7 \% \text {, without pre- } \\
\text { operative irradiation } \\
25.6 \% \text { ) }\end{array}$ & - & - \\
\hline Morita et al. [11] & 94 & Squamous carcinoma & Serial section & 20.2 & - & - \\
\hline Pesko et al. [31] & 54 & Squamous carcinoma & Serial section & 31.5 & $\begin{array}{l}\text { Cranial: } 1.0-5.0 \mathrm{~cm} \text {, mean } 3.2 \mathrm{~cm} \\
\text { Caudal: } 1.5-5.0 \mathrm{~cm} \text {, mean } 3.3 \mathrm{~cm}\end{array}$ & - \\
\hline Morita et al. [12] & 114 & Squamous carcinoma & Serial section & 20.2 & - & - \\
\hline
\end{tabular}

Note: -, Not assessed; MOL, multicentric occurring lesions

d) VI: is defined as the infiltration of tumor cells into lymph and blood vessels, as well as tumor embolus formation. Lam et al. [13] reported that the incidence of VI in ESCC was $16.67 \%$ (16/96), most of which occurred at the base of the tumor but was occasionally found distal from the primary tumor, at a maximum distance of $5 \mathrm{~cm}$. The incidence of VI in early-stage ESCC was 13.89\% (15/108) [14] and 39.1\% $(143 / 366)$ in advanced disease [15]. The incidence of VI in esophageal adenocarcinoma was $49.9 \%$ $(229 / 459)$ [16]. All of these studies demonstrated that VI is an important prognostic factor; however, none of these studies assessed the distance of VI sites from the primary tumor. Brücher found that when lymph vessels around the tumor were infiltrated, especially laterally, a higher likelihood of local-regional lymph node metastases was observed [15].

e) LNMM and ITC: LNMM refers to $0.2-2 \mathrm{~mm}$ of tumor cell invasion into a lymph node, whereas less than $0.2 \mathrm{~mm}$ of infiltration is defined as ITC. Both LNMM and ITC are occult metastases that cannot be found by routine pathologic examination. With the development of immunohistochemistry techniques, more occult lymph node metastases have been detected. Using immunohistochemistry, Koenig et al. [17] assessed lymph node-negative patients with resectable esophageal carcinoma, including squamous cell carcinoma and adenocarcinoma, and observed that the incidence of LNMM was 34.2\% (25/73). Patients with LNMM had a five-year overall survival probability of $30 \%$, which was significantly lower than patients without LNMM, in whom the five-year 
survival rate was $76 \%(P=0.02)$. However, this study did not collect data regarding the LNMM site. Natsugoe and colleagues [18] studied the locations of solitary lymph node metastases and micrometastases in ESCC and noted that the locations of the two types of nodal metastases were distributed similarly. Lymph node metastases were limited to the area of the recurrent nerve in the upper thoracic esophagus and to paraesophageal and perigastric nodes in the middle or lower thoracic esophagus; investigators also found that the incidence of LNMM increased with tumor depth.

f) PNI: is defined as cancer cell infiltration into the perineurium or fasciculus, and can be detected at the boundary of the deepest tumor invasion. Tanaka et al. reported an incidence of $46.2 \%(48 / 104)$ of PNI in resected ESCC and found that PNI is an important prognostic factor for local relapse [19]. However, Sarbia et al. reported that the incidence of PNI was 26.1\% (42/161) among patients with the same histology and concluded that PNI was not a prognostic factor based on univariate and multivariate survival analyses [20]. Recently, Chen et al reported that PNI was identified in $47.7 \%$ (209/433) cases, and they concluded that PNI can play a role as an independent prognostic factor of outcomes [21]. Though the results of those researches of PNI remain controversial, we think PNI will be a new maker for prognosis of ESCC in the future.

\section{(2) Clinical outcomes}

In radiation therapy, the expansion margin from GTV to CTV is solely based on the consideration of subclinical lesions around the primary tumor. Our preliminary research into simulated plans (using optimal FLT and FDG PET/CT thresholds) for squamous cell carcinoma of the thoracic esophagus found that an extended margin influences both organ-at-risk (OAR) and planning target volumes, especially for those patients with larger tumors, will affect the OARs adjacent to the target significantly. Powerful imaging approaches, such as FDG PET/CT, and advanced treatment technology such as image guided radiotherapy, incorporated into radiotherapy for ESCC, can be utilized to decrease the internal target volume and setup error, thus undoubtedly bringing dosimetric benefits to both the target and OARs [22]. Our preliminary research has shown that even with a little larger GTV, will affect the PTV significantly, and also will influence organ-at-risk (OAR) as a induced result. And the technique of PET imaging, (FLT versus FDG, for example) can be further refined to reveal more subclinical disease and improve target delineation (Figure 1).
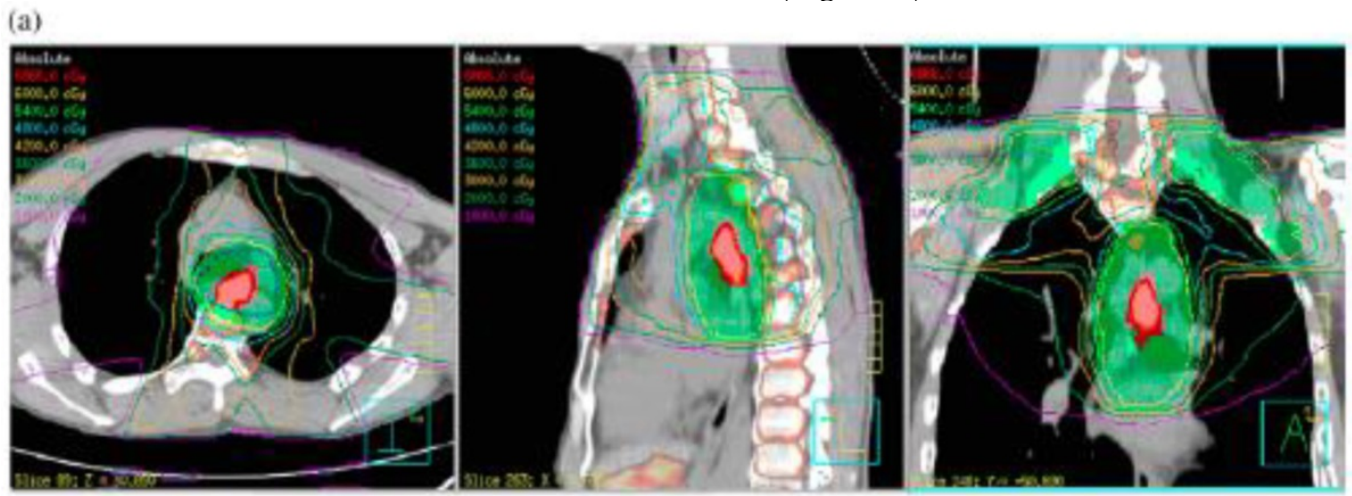

(b)
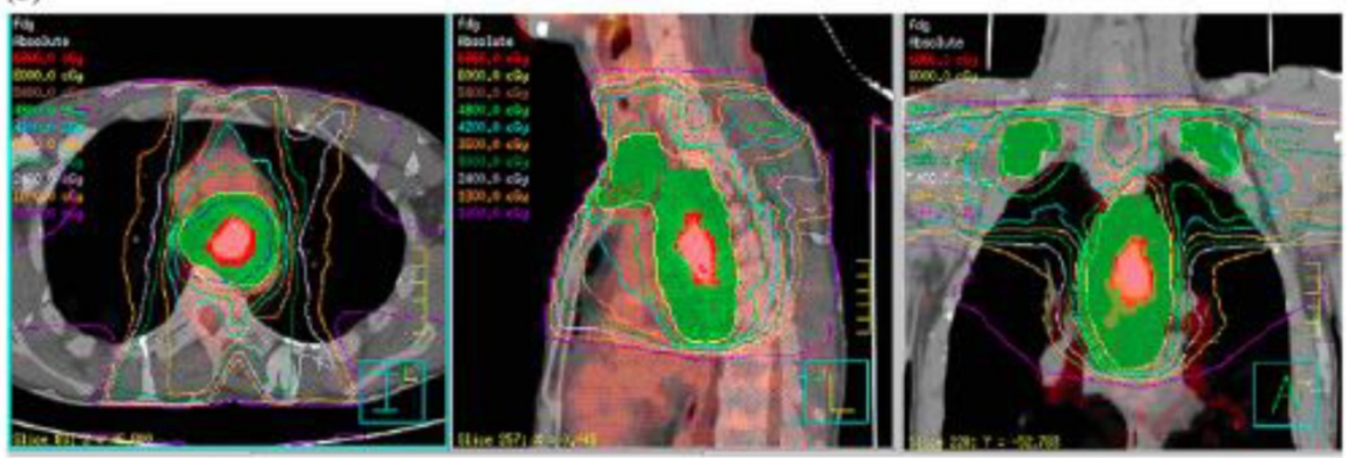

Figure 1. Treatment planning simulated with FLT and FDG positron emission tomography (PET)/computed tomography (CT) for a 72-year-old male patient with upper thoracic esophageal SCC. a. FLT PET/CT image based 7-beam IMRT irradiation field including primary tumor and prophylactic supraclavicular nodes region $\left(\mathrm{SUV}=1.4\right.$, L Tumor $\left.=4.68 \mathrm{~cm}, \mathrm{GTV}=15.95 \mathrm{~cm}^{3}, \mathrm{PTV}=650.33 \mathrm{~cm}^{3}\right)$,B. FDG PET/CT image based 7-beam IMRT irradiation field including primary tumor and prophylactic supraclavicular nodes region (SUV $=2.5$, LTumor $\left.=5.1 \mathrm{~cm}, \mathrm{GTV}=17.19 \mathrm{~cm}^{3}, \mathrm{PTV}=708.21 \mathrm{~cm}^{3}\right)$. The difference between FLT and FDG PET/CT induced GTV is only 1.24 $\mathrm{cm}^{3}$, while that's of PTV is $57.88 \mathrm{~cm}^{3}$. It has shown that with even with a little larger GTV, will affect the PTV significantly, and also will influence organ-at-risk (OAR) as a induced result. (Cited from reference 22, with permission by Elsevier.) 


\section{(a) Subclinical lesions and the primary CTV (CTVp)}

Pathologic research has shown that DI, IMM, MOL, VI and PNI are subclinical lesions that should be included in CTVp. Radiotherapy techniques have been developed that recommend the use of enlarged fields (e.g., whole-esophagus or whole-mediastinum) to treat secondary lesions located far from the primary tumor. Both the Radiation Therapy Oncology Group (RTOG) 85-01 trial and the RTOG 94-05 trial employed enlarged radiation fields, initial target volume including supraclavicular fossae to the esophagogastric junction, and $5 \mathrm{~cm}$ margin beyond superior and inferior of the primary tumor, respectively. However, these studies did not demonstrate improved local control or survival despite causing intolerable toxicities [23]. If there is no benefit to using enlarged irradiation field, what outcomes may be expected after involved field treatment? Button et al. [24] performed a retrospective study on 145 patients to assess the first site of disease relapse after definitive chemoradiotherapy. The RT planning target volume included the GTV, with $1.5-\mathrm{cm}$ lateral and $3-\mathrm{cm}$ superior-inferior margins. Relapse occurred locally (within the RT field) in 55 patients, distantly (metastatic) in 13 patients, and as a combination of local and distant disease in 14 patients. The local relapse rates were not influenced by tumor stage, lymph node status, or disease length. The GTV to planning target volume (PTV) margins in this study appeared adequate. Interestingly, only 3 patients relapsed in regions adjacent to the RT fields. To improve local control, it seems that larger field margins would unlikely have been clinically effective in these cases. The results of Gao et al. [25], who studied the CTVp for esophageal squamous cell cancer using pathological analysis, also support this view. This study analyzed the extent of microscopic spread within the esophagus and concluded that the recommended CTV margin should be $<30 \mathrm{~mm}$ in approximately $94 \%$ of cases of esophageal cancer, although the investigators did not note the occurrence of each secondary lesion. All previous studies suggest that smaller margins are acceptable and do not increase the local failure risk. However, these results are limited by the sample size, and some questions remain unanswered.

\section{(b) CTV for lymph nodes (CTVn)}

The esophagus has an extensive lymph drainage region, with draining lymph nodes spread in the region between the supraclavicular and upper abdomen. The lymph nodes around the esophagus are invaded in the early stages of disease development, and skip metastases in regional lymph nodes are common in esophageal carcinoma. The prophylactically irradiated region should include all potential metastases, although LNMM and ITC cannot be detected by conventional imaging methods. Nishimaki et al. [26] retrospectively analyzed 51 cases of early (superficially invasive) carcinoma of the esophagus in patients who underwent extended radical esophagectomy and found that in 29 cases with lymph node metastasis, the rate of skip metastases was $24 \%$. Hosch et al. [27] studied a total of 1,584 resected lymph nodes obtained from 86 patients with resected esophageal carcinoma and found a $34 \%$ probability of skip metastasis at one or multiple stations. For thoracic esophageal SCC, the incidence of lymph node metastasis was $70 \%$, and the high risk regions were paracardiac nodes of the stomach, nodes of lesser gastric curvature, and the nodes of right laryngeal nerve. In total, $35 \%$ of patients had positive cervical lymph nodes, and $45 \%$ had positive mediastinal and abdominal lymph nodes. The most commonly involved mediastinal sites were the bilateral laryngeal nerves, subcarinal and paraesophageal regions, and the most commonly involved abdominal site was the paracardiac lymph nodes.

The need to prophylactically irradiate areas at high risk of metastasis must be weighed against potential treatment toxicities. Is preventive irradiation of a CTVn for $\mathrm{N}_{0}$ stage patients necessary? Nakamura et al. [28] studied postoperative pathological results in 95 patients with clinical $\mathrm{T}_{1}-\mathrm{T}_{3} \mathrm{~N}_{0} \mathrm{M}_{0}$ thoracic esophageal cancers. They found that the rates of lymph node metastases for the upper, middle, lower and abdominal esophagus were $37.5 \%, 32.5 \%, 46 \%$ and $70 \%$, respectively; additionally, they suggested that in patients with upper and middle thoracic esophageal tumors, prophylactic radiation of abdominal lymph nodes was unnecessary and that irradiation of the supraclavicular region was not necessary in patients with middle and lower thoracic esophageal tumors. Huang et al. [29] retrospectively analyzed the pattern of lymph node metastasis in 1077 patients with thoracic ESCC who had undergone esophagectomy and lymphadenectomy and suggested a detailed technique for contouring a prophylactic nodal irradiation volume. For upper thoracic esophageal carcinomas, the superior prophylactic nodal irradiation volume should include the cervical paraesophageal and supraclavicular lymph nodes, and the superior margin should include the subcarinal lymph nodes. For lower thoracic esophageal carcinomas, the superior margin should include the subcarinal lymph nodes, and the inferior margin should include the left gastric lymph nodes and common hepatic artery lymph nodes. For middle thoracic esophageal carcinomas, the prophylactic treatment volume should be customized de- 
pending on the clinical circumstances; more thorough coverage of the mediastinal lymph nodes should be considered, especially in patients who are generally in good condition. As shown in figure 2.
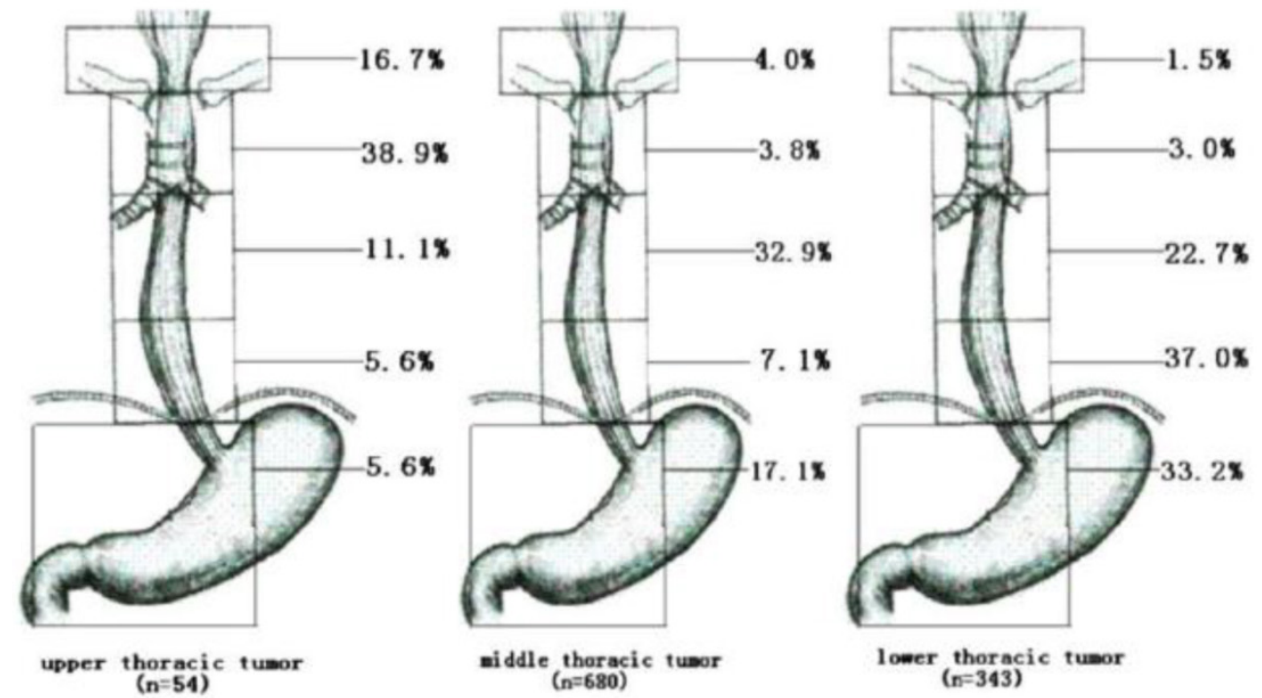

Figure 2. Rate of LNM to different regions according to the location of the primary tumor (Cited from reference 29, with permission by Elsevier.)

\section{Conclusion}

In summary, the CTV of esophageal carcinoma should cover the primary tumor and all detected secondary lesions that must be treated. Rarely, individual lesions may be located distant from the primary tumor, therefore empirical irradiation of the whole esophagus or mediastinum is likely unnecessary. Adequate margins within at least $3 \mathrm{~cm}$ of gross tumor volume and detected secondary lesions will also ensure that occult secondary lesions close to the primary tumor within the esophagus are also covered. The precise method of creating reasonable CTV contours is to combine advanced imaging mediums (e.g., PET/CT, EUS, etc.) along with clinical features such as the tumor's pathological type, differentiation, $\mathrm{T}$ stage, length and lymph node status, to detect and predict subclinical lesions with sufficient margin, thereby increasing local control and decreasing the risk of complications. In a recent report, involved field irradiation was recommended, with a suggested $3 \mathrm{~cm}$ CTVp super-inferior margin expansion from GTVp, and the CTVn is defined as the GTVn plus a 0.5-1.0 $\mathrm{cm}$ radial margin, in the expectation that treatment-related toxicities would decline as the irradiation volume is diminished [30]. Therefore, we believe the future trends in the radiotherapeutic approach to ESCC will include moving towards a reduction in the CTV margin and, perhaps, dose-escalation. The long-term result of this new approach has yet to be acquired and controversy will likely remain regarding this topic for some time.

\section{Acknowledgment}

This Work Was Supported By Natural Science Foundation Of China, No.81101699, And Shandong Province Natural Science Foundation,No.ZR2015HM041 And ZR2011HL028, And Shandong Province Key R\&D Program No.2015GSF118017, And Shandong Medical And Health Science And Technology Development Plan, No.2013WSA18002.

\section{Competing Interests}

The authors have declared that no competing interest exists.

\section{References}

1. Cooper JS, Guo MD, Herskovic A, et al. Chemoradiotherapy of locally advanced esophageal cancer: long-term follow-up of a prospective randomized trial (RTOG 85-01). Radiation Therapy Oncology Group. JAMA. 1999;281:1623-7.

2. Minsky BD, Pajak TF, Ginsberg RJ, et al. INT 0123 (Radiation Therapy Oncology Group 94-05) phase III trial of combined-modality therapy for esophageal cancer: high-dose versus standard-dose radiation therapy. J Clin Oncol. 2002;20:1167-74.

3. Kuwano H, Masuda N, Kato H, et al. The subepithelial extension of esophageal carcinoma for determining the resection margin during esophagectomy: a serial histopathologic investigation. Surgery. 2002;131(Suppl 1):S14-21.

4. Tsutsui S, Kuwano H, Watanabe M, et al. Resection margin for squamous cell carcinoma of the esophagus. Ann Surg. 1995;222:193-202.

5. Nishimaki T, Suzuki T, Tanaka Y, et al. Intramural metastases from thoracic esophageal cancer: local indicators of advanced disease. World J Surg. 1996;20:32-7.

6. Takubo K, Sasajima K, Yamashita K, et al. Prognostic significance of intramural metastasis in patients with esophageal carcinoma. Cancer. 1990;65:1816-9.

7. Kato $\mathrm{H}$, Tachimori $\mathrm{Y}$, Watanabe $\mathrm{H}$, et al. Intramural metastasis of thoracic esophageal carcinoma. Int J Cancer. 1992;50:49-52.

8. Kuwano H, Watanabe $\mathrm{M}$, Sadanaga $\mathrm{N}$, et al. Univariate and multivariate analyses of the prognostic significance of discontinuous intramural metastasis in patients with esophageal cancer. J Surg Oncol. 1994;57:17-21.

9. Yuasa N, Miyake H, Yamada T, et al. Prognostic significance of the location of intramural metastasis in patients with esophageal squamous cell carcinoma. Langenbecks Arch Surg. 2004;389:122-7. 
10. Kuwano H, Ohno S, Matsuda H, et al. Serial histologic evaluation of multiple primary squamous cell carcinomas of the esophagus. Cancer. 1988;61:1635-8.

11. Morita M, Kuwano H, Yasuda M, et al. The multicentric occurrence of squamous epithelial dysplasia and squamous cell carcinoma in the esophagus. Cancer. 1994;74:2889-95.

12. Morita M, Araki K, Saeki H, et al. Risk factors for multicentric occurrence of carcinoma in the upper aerodigestive tract-analysis with a serial histologic evaluation of the whole resected-esophagus including carcinoma. J Surg Oncol. 2003;83:216-21.

13. Lam KY, Ma LT, Wong J. Measurement of extent of spread of oesophageal squamous carcinoma by serial sectioning. J Clin Pathol. 1996;49:124-9.

14. Amano T, Matsumoto T, Hayashi T, et al. Subepithelial extension of squamous cell carcinoma in the esophagus: histopathological study using D2-40 immunostaining for 108 superficial carcinomas. Pathol Int. 2007;57:759-64.

15. Brücher BL, Stein HJ, Werner $M$, et al. Lymphatic vessel invasion is an independent prognostic factor in patients with a primary resected tumor with esophageal squamous cell carcinoma. Cancer. 2001;92:2228-33.

16. von Rahden $\mathrm{BH}$, Stein $\mathrm{HJ}$, Feith $\mathrm{M}$, et al. Lymphatic vessel invasion as a prognostic factor in patients with primary resected adenocarcinomas of the esophagogastric junction. J Clin Oncol. 2005;23:874-9.

17. Koenig AM, Prenzel KL, Bogoevski D, et al. Strong impact of micrometastatic tumor cell load in patients with esophageal carcinoma. Ann Surg Oncol. 2009;16:454-62.

18. Natsugoe $\mathrm{S}$, Matsumoto $\mathrm{M}$, Okumura $\mathrm{H}$, et al. Initial metastatic, including micrometastatic, sites of lymph nodes in esophageal squamous cell carcinoma. J Surg Oncol. 2005;89:6-11.

19. Tanaka A, Matsumura E, Yosikawa $\mathrm{H}$, et al. An evaluation of neural invasion in esophageal cancer. Surg Today. 1998;28:873-8.

20. Sarbia M, Porschen R, Borchard F, et al. Incidence and prognostic significance of vascular and neural invasion in squamous cell carcinomas of the esophagus. Int I Cancer. 1995;61:333-6.

21. Chen JW, Xie JD, Ling YH, et al. The prognostic effect of perineural invasion in esophageal squamous cell carcinoma. BMC Cancer.2014; 14:313.

22. Han D, Yu J, Yu Y, et al. Comparison of (18)F-fluorothymidine and (18)F-fluorodeoxyglucose PET/CT in delineating gross tumor volume by optimal threshold in patients with squamous cell carcinoma of thoracic esophagus. Int J Radiat Oncol Biol Phys. 2010;76:1235-41.

23. Minsky BD. Primary combined-modality therapy for esophageal cancer. Oncology (Williston Park). 2006;20:497-505.

24. Button MR, Morgan CA, Croydon ES, et al. Study to determine adequate margins in radiotherapy planning for esophageal carcinoma by detailing patterns of recurrence after definitive chemoradiotherapy. Int J Radiat Oncol Biol Phys. 2009;73:818-23.

25. Gao XS, Qiao X, Wu F, et al. Pathological analysis of clinical target volume margin for radiotherapy in patients with esophageal and gastroesophageal junction carcinoma. Int J Radiat Oncol Biol Phys. 2007;67:389-96.

26. Nishimaki T, Suzuki T, Kanda T, et al. Extended radical esophagectomy for superficially invasive carcinoma of the esophagus. Surgery. 1999;125:142-7.

27. Hosch SB, Stoecklein NH, Pichlmeier U, et al. Esophageal cancer: the mode of lymphatic tumor cell spread and its prognostic significance. J Clin Oncol. 2001;19:1970-5.

28. Nakamura T, Hatooka S, Kodaira T, et al. Determination of the irradiation field for clinical T1-T3N0M0 thoracic/abdominal esophageal cancer based on the postoperative pathological results. Jpn J Clin Oncol. 2009;39:86-91.

29. Huang W, Li B, Gong $\mathrm{H}$, et al. Pattern of lymph node metastases and its implication in radiotherapeutic clinical target volume in patients with thoracic esophageal squamous cell carcinoma: a report of 1077 cases. Radiother Oncol. 2010:95:229-33

30. Jiang L, Zhao X, Meng X, Yu J. Involved field irradiation for the treatment of esophageal cancer: is it better than elective nodal irradiation? Cancer Lett. 2015;357:69-74. 